\title{
Ca (II)-EDTA shows antimicrobial activity against periodontopathic bacteria
}

\author{
Tadashi Miura, Koji Tanabe, Masao Yoshinari
}

Division of Oral Implants Research, Oral Health Science Center, Tokyo Dental College, Chiba, Japan

Email: tamiura@tdc.ac.jp

Received 18 October 2011; revised 28 November 2011; accepted 7 December 2011

\begin{abstract}
Ethylenediamine-N,N,N',N'-tetraacetic acid calcium (II) disodium salt (Ca (II)-EDTA) was investigated for its antibacterial activity against the periodontal pathogens Aggregatibacter actinomycetemcomitans, Prevotella intermedia and Porphyromonas gingivalis. We determined the minimum inhibitory concentrations (MIC) of Ca (II)-EDTA and its bactericidal activity. Ethylenediamine-N,N,N',N'-tetraacetic acid calcium (II) disodium salt inhibited the growth of all the periodontopathic bacteria tested in broth. An MIC of 60 mM was the most effective against $P$. gingivalis. An adenosine triphosphate bioluminescence assay revealed that Ca (II)-EDTA showed bactericidal activity against the bacteria tested in a time-dependent manner. To determine its safety in mammalian cells, we investigated the viability of murine L929 cells subjected to Ca (II)-EDTA treatment. At $75 \mathrm{mM}$, $93 \% \pm 0.13 \%$ of the cells survived. These results indicate that Ca (II)-EDTA is a candidate chelating agent for prevention of infection by periodontopathic bacteria.
\end{abstract}

Keywords: Chelating Agent; Periodontopathic Bacteria; Peri-Implantitis; Antimicrobial Activity

\section{INTRODUCTION}

The formation of microbial biofilm around a dental prosthesis or implant is a major cause of periodontal disease, including peri-implantitis, defined as imflammation or infection around an implant with accompanying bone loss. Five species of periodontal pathogen have been detected around titanium implants [1]. Porphyromonas gingivalis [2] and Aggregatibacter actinomycetemcomitans [3] are believed to be major etiologic bacteria in human periodontitis. Prevotella intermedia [4] has also been associated with human periodontal disease. This indicates the importance of maintaining biofilm-free surfaces on the sub-gingival and supra-gingival portions of a dental implant if peri-implantitis and periodontitis are to be prevented. Research at our laboratory has focused on developing a system of defense against infection on dental material surfaces [5]. Decreasing plaque accumulation has been emphasized in the prevention of periodontal disease, including peri-implantitis [6]. Antimicrobial materials may offer a means of reducing the oral bacteria involved in the development of oral disease.

In an earlier study, we found that one advantage of antimicrobial peptides was that they did not act as antigens against the host [7]. One of the aims of our ongoing research is to create a defense system against peri-implantitis, and we have recently been exploring the antimicrobial potential of low-molecular materials affixed to the surfaces of dental materials [8]. We have reported the anti-periodontopathic activity of the antimicrobial peptide protamine [9]. Although protamine has shown strong inhibitory activity against growth of $P$. gingivalis, its antimicrobial force appears to be short-lived, and problems remain with regard to its sustained release. Therefore, we are searching for other low-molecular substances which can exert a more stable antibacterial effect.

In the present study, we investigated the inhibitory effect of ethylenediamine-N,N,N',N'-tetraacetic acid calcium (II) disodium salt (Ca (II)-EDTA) on growth of periodontopathic bacteria. Ethylenediaminetetraacetic acid (EDTA) inhibits enzymatic reactions by trapping metal ions, thus exerting a chelating effect $[10,11]$. Normally, EDTA is present in the form of disodium salt. Effective as a chelating agent, even at low doses, it has been incorporated into a variety of products and cosmetics.

Ethylenediaminetetraacetic acid has been reported to suppress Escherichia coli by removal of the metal ions required for its growth [12]. Although EDTA is useful as an antidote for lead poisoning, the Ministry of the Environment in Japan has reported that there are risks associated with its use related to zinc or calcium deficiency when ingested in high doses [13]. Mutagenicity studies in animals have produced both positive and negative results $[14,15]$. However, Ca (II)-EDTA was found to be harmless with 2-year oral administration as a chelating reagent in rat [16]. Therefore, it was prescribed by the 
FAO/WHO Joint Expert Committee on Food Additives (JECFA) that EDTA should be in the form of calcium rather than disodium salt when added to canned or bottled food as an antioxidant. The purpose of this study was to investigate the potential of Ca (II)-EDTA as an antimicrobial agent against periodontopathic bacteria and determine its safety in mammalian cells.

\section{MATERIALS AND METHODS}

\subsection{Materials}

Ethylenediamine-N,N,N',N'-tetraacetic acid calcium (II) disodium salt was obtained from Dojindo LABORATORIES (Kumamoto, Japan). For the cell proliferation assay, Ca (II)-EDTA was solubilized in Dulbecco's modified essential medium (DMEM, Gibco, Grand Island, NY, USA), which was then used as a part of the culture medium described below. To evaluate minimum inhibitory concentration (MIC), Ca (II)-EDTA was solubilized in the broth described below for liquid culture of bacteria.

\subsection{Bacteria and Culture Conditions}

For plate culture, the bacteria tested in this study were grown on plates containing Tryptic soy agar $\left(40 \mathrm{~g} \cdot \mathrm{L}^{-1}\right.$; Becton Dickinson and Company, Sparks, MD, USA) supplemented with $10 \%$ defibrinated horse blood, hemin (5 $\left.\mathrm{g} \cdot \mathrm{L}^{-1}\right)$, and menadione $\left(0.5 \mathrm{~g} \cdot \mathrm{L}^{-1}\right)$. Preculture was performed in an anaerobic chamber $\left(\mathrm{N}_{2}: 80 \%, \mathrm{H}_{2}: 10 \%\right.$, $\mathrm{CO}_{2}: 10 \%$ ) at $37^{\circ} \mathrm{C}$. For liquid culture, $P$. gingivalis ATCC 33277 (ATCC, American Type Culture Collection) and $P$. intermedia ATCC 25611 were cultured in Trypticase soy broth $\left(30 \mathrm{~g} \cdot \mathrm{L}^{-1}\right.$; Becton Dickinson and Company, Sparks, MD, USA) supplemented with hemin ( $5 \mathrm{~g} \cdot \mathrm{L}^{-1}$; Sigma Chemical Co., St Louis, MO) and menadione $\left(0.5 \mathrm{~g} \cdot \mathrm{L}^{-1}\right.$; Wako Pure Chemical Industries, Osaka, Japan). A. actimomycetemcomitans 310 a was cultured in Todd Hewitt Broth $\left(30 \mathrm{~g} \cdot \mathrm{L}^{-1}\right.$; Becton Dickinson and Company) supplemented with Yeast Extract (10 $\mathrm{g} \cdot \mathrm{L}^{-1}$; Becton Dickinson and Company). Each precultured colony was inoculated into a liquid broth and incubated for 2 to 4 days under the conditions described above.

\subsection{Evaluation of Minimum Inhibitory Concentration}

Broths containing Ca (II)-EDTA were used to determine MIC. Concentration of Ca (II)-EDTA was adjusted by stepwise dilution in increments of $10 \mathrm{mM}$ from $50 \mathrm{mM}$ to $100 \mathrm{mM}$. Each bacterial strain was inoculated into the broth and then incubated for 3 - 7 days in an anaerobic chamber at $37^{\circ} \mathrm{C}$. Minimum inhibitory concentration was defined as the lowest concentration of Ca (II)-EDTA that would inhibit the visible growth of the microorganisms after incubation. The experiments were performed four times to confirm the reliability of the data.

\subsection{Antibacterial Activity of Ca (II)-EDTA against Periodontopathic Bacteria}

Periodontopathic bacteria were anaerobically grown at $37^{\circ} \mathrm{C}$ to the early stationary phase in the broth described above. The harvested cells were washed once in autoclaved water and then resuspended in freshly autoclaved water containing adequate concentrations of Ca (II)-EDTA. Bacterial cell suspensions were incubated at $37^{\circ} \mathrm{C}$ and examined for bacterial cell viability every $30 \mathrm{~min}$ over a $120 \mathrm{~min}$ period. Bacterial cell viability was determined by adenosine triphosphate bioluminescence assay using the BacTiter-Glo Microbial Cell Viability Assay kit (Promega, Madison, USA). Briefly, a volume of BacTiter-Glo reagent equal to the volume of each suspension was added and briefly mixed. The luminescence of the solution was then recorded by using the AUTO-LUMICOUNTER Model 1422EX (Microtec Co., LTD, Funabashi, Japan). The value obtained was expressed as the ratio to that at the start of incubation. The results were expressed as the mean $\pm \mathrm{SD}$ of three experiments.

\subsection{Mammalian Cell Viability Assay}

Murine L929 cells derived from connective tissue (ATCC, Rockville, MD, USA) were used in this study. The culture medium consisted of DMEM supplemented with 10\% fetal bovine serum (Sigma Chemical Co., St Louis, MO, USA) and antibiotics. Cells subcultured at $37^{\circ} \mathrm{C}$ in a humidified atmosphere with $5 \% \mathrm{CO}_{2}$ were suspended in DMEM at a concentration of $2 \times 10^{8}$ cells $\cdot \mathrm{L}^{-1}$. An aliquot of $2 \times 10^{-4} \mathrm{~L}$ of cells was dispensed in the wells of a 96-well plate and then incubated for $4 \mathrm{hr}$ at $37^{\circ} \mathrm{C}$ in a humidified atmosphere with $5 \% \mathrm{CO}_{2}$. The medium was replaced with medium containing $\mathrm{Ca}$ (II)EDTA at concentrations adjusted by stepwise dilution and incubated for another one day. After completion of cultivation, cell viability was determined by using the Premix Proliferation Assay system (TAKARA Bio Inc., Ohtsu, Japan). Briefly, a $20-\mu \mathrm{L}$ aliquot of Premix WST-1 was added to each well. The cells were then incubated under humidified atmospheric pressure $\left(37^{\circ} \mathrm{C}, 5 \% \mathrm{CO}_{2}\right)$ for 3 to $4 \mathrm{hr}$. Absorbance was measured at $440 \mathrm{~nm}$ by using the SpectraMax Microplate Reader (MDS Analytical Technologies, Sunnyvale, CA), subtracting absorbance of the background control at $650 \mathrm{~nm}$. The experiments were performed in triplicate. The data were expressed as the survival rate.

\subsection{Statistical Analysis}

Data were analyzed for statistical significance using a 
two-way analysis of variance followed by the Scheffe test for multiple comparisons including factor A $(0,30$, 60,90 , and $120 \mathrm{~min}$ ) arising from differences along incubation time, and factor B (0 and $100 \mathrm{mM})$ based on differences in the concentration of Ca (II)-EDTA, using the statistical analysis software package Excel Statistics (2006, SSRI, Japan).

\section{RESULTS AND DISCUSSION}

\subsection{Inhibitory Effect of Ca (II)-EDTA against Periodontopathic Bacteria}

As shown in Table 1, Ca (II)-EDTA showed an inhibitory effect on growth of all the periodontopathic bacteria tested, with inhibitory effect greatest on growth of the $P$. gingivalis strain. The MIC value for $P$. gingivalis was 60 $\mathrm{mM}$, while that for $A$. actinomycetemcomitans and $P$. intermedia required a higher concentration, at $70 \mathrm{mM}$. These findings suggest that Ca (II)-EDTA exhibits selective inhibitory action against growth of periodontopathic bacteria.

To further investigate its potential to inhibit growth of periodontopathic bacteria, the bactericidal activity of $\mathrm{Ca}$ (II)-EDTA was assessed. As shown in Figure 1, Ca (II)-EDTA showed bactericidal activity in a time-dependent manner against all the bacteria tested. A highly significant difference was observed in inhibitory action between factors $\mathrm{A}(0,30,60,90$ and $120 \mathrm{~min})$ and $\mathrm{B}(0$ and $100 \mathrm{mM}$ ) of the two-way analysis of variance against all bacteria tested. Bacterial viable cells significantly

Table 1. Effect of Ca (II)-EDTA on growth of periodontopathic bacteria and minimum inhibitory concentration of reagent.

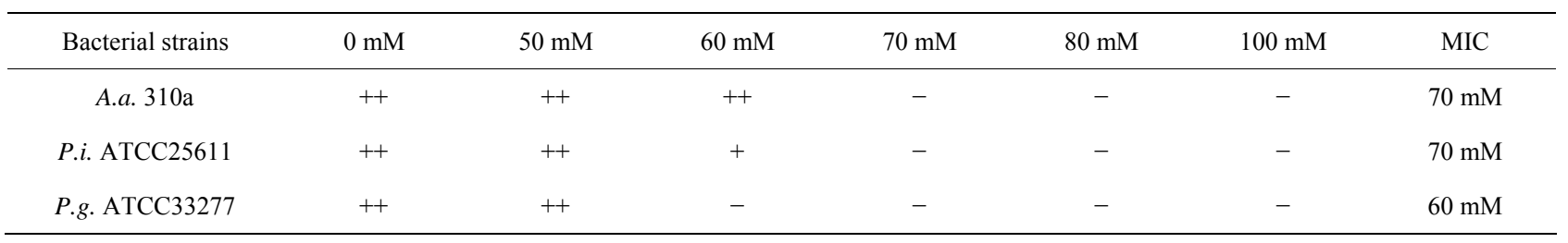

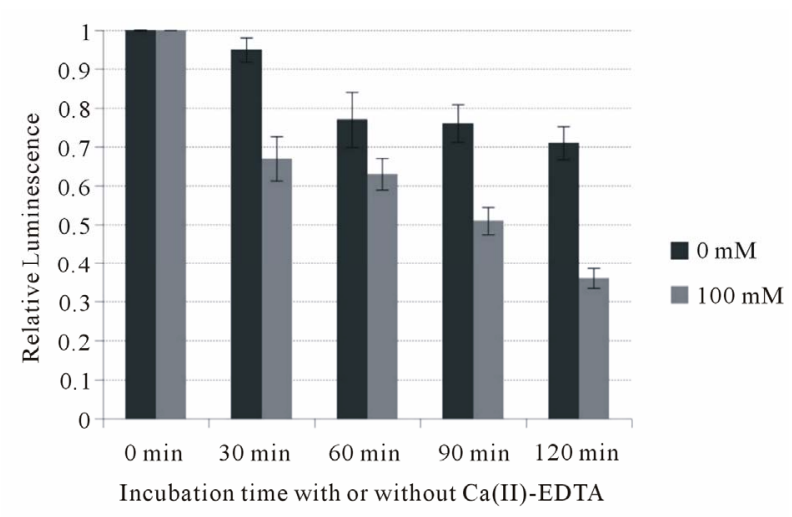

(a)

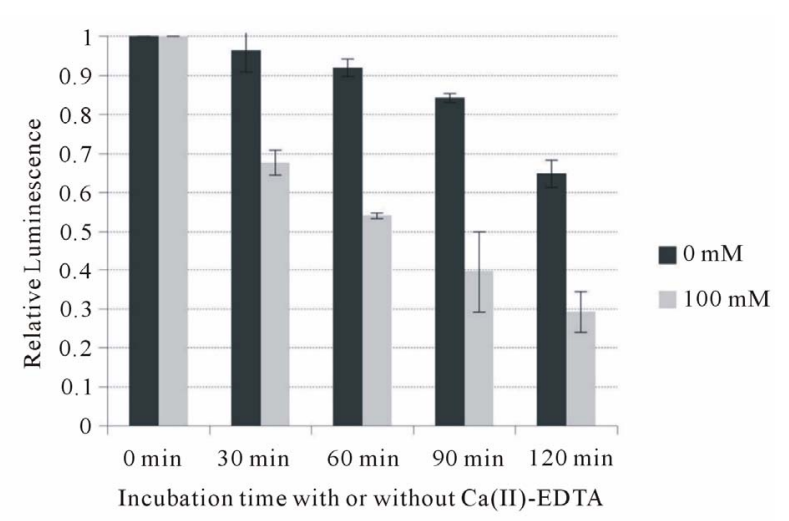

(b)

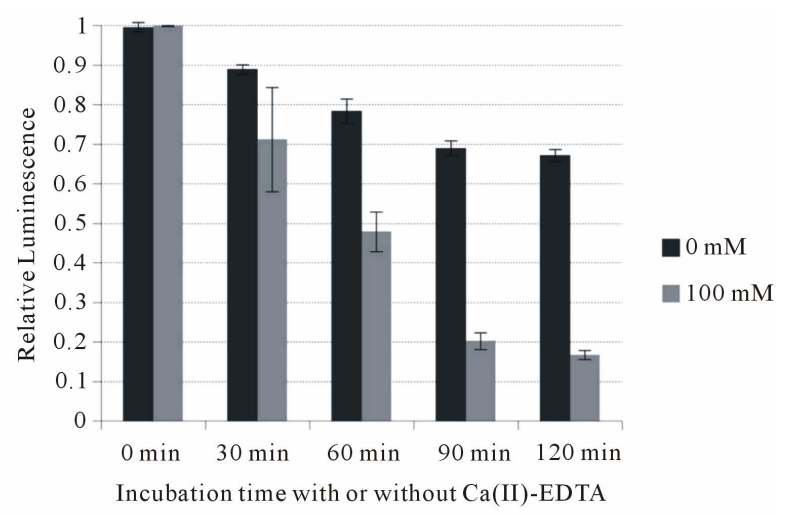

(c)

Figure 1. Influence of Ca (II) EDTA on cell viability of periodontopathogens. (a) A. actimomycetemcomitans 310a; (b) P. intermedia ATCC 25611; (c) P. gingivalis ATCC 33277. 
decreased since the bacteria have been exposed to $\mathrm{Ca}$ (II)-EDTA $(p<0.01)$. At $100 \mathrm{mM}$, higher than the MIC, $\mathrm{Ca}$ (II)-EDTA reduced the number of A actimomycetemcomitans cells to less than $40 \%$ of that at $0 \mathrm{~min}$ incubation after 2 hours incubation. It also inhibited growth of an even larger number of $P$. intermedia (to less than $30 \%$ ) and $P$. gingivalis cells (to less than $20 \%$ ). In addition, two-factor interaction also showed a highly significant difference. These data support that it is possible to suppress their growth with time of exposure of $\mathrm{Ca}$ (II)-EDTA against the bacteria. This indicates that this chelating reagent exerts an inhibitory effect on the growth of periodontopathic bacteria.

\subsection{Cell Viability Assay against Ca (II)-EDTA in Mammalian Cells}

As shown in Figure 2, the survival rate of murine L929 cells declined in a concentration-dependent manner. At $75 \mathrm{mM} \mathrm{Ca}$ (II)-EDTA, 93\% of the cells survived. This suggests that this reagent would be harmless at an MIC of $60 \mathrm{mM}$ or $70 \mathrm{mM}$ in mammalia. In this study, we found that Ca (II)-EDTA exerted an inhibitory effect on periodontal pathogens. Further investigation is necessary, however, to elucidate the properties of this chelating reagent, using the immobilization methods established at our laboratory, for example. Moreover, the sustained release of this chelating agent must be examined. Of interest, also, are the functional mechanisms involved in its inhibition of growth of periodontopathic bacteria. One of our goals is to develop a defense system against periimplantitis. We believe that application of Ca (II)-EDTA to dental implants would offer advantages in the prevention of periodontal diseases such as peri-implantitis and oral care.

\section{ACKNOWLEDGEMENTS}

The authors would like to thank Associate Professor Jeremy Williams, Tokyo Dental College, for his assistance with the English of this

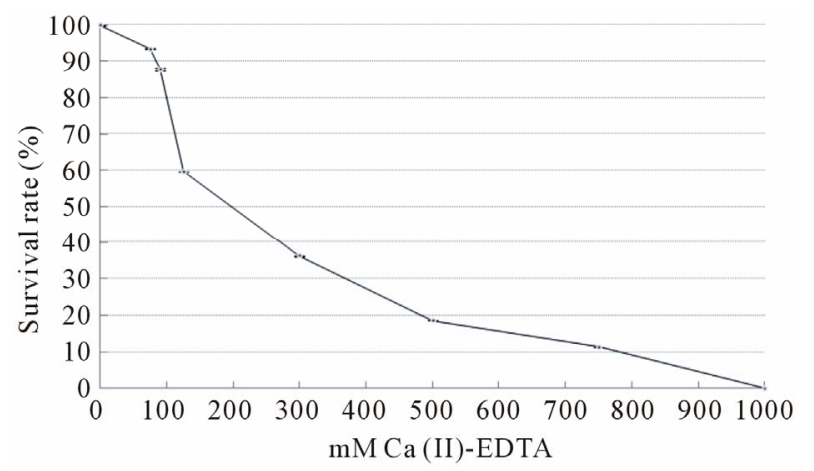

Figure 2. Cell viability assay on various concentrations of $\mathrm{Ca}$ (II)-EDTA ( $24 \mathrm{~h}$ ). Standard deviation is expressed by bar. For example, at $75 \mathrm{mM}, 93 \% \pm 0.13 \%$ of cells survived. manuscript. We would also like to thank Dr. Huang Yi, Tokyo Dental College, for her assistance with the experiments.

\section{REFERENCES}

[1] Sumida, S., Ishihara, K., Kishi, M. and Okuda, K. (2002) Transmission of periodontal disease-associated bacteria from teeth to osseointegrated implant regions. International Journal of Oral \& Maxillofacial Implants, 17, 696-702.

[2] Slots, J. and Genco, R.J. (1984) Black-pigmented Bacteroides species, Capnocytophaga species, and Actinobacillus actinomycetemcomitans in human periodontal disease: Virulence factors in colonization, survival, and tissue destruction. Journal of Dental Research, 63, 412-421. doi:10.1177/00220345840630031101

[3] Dzink, J.L., Tanner, A.C., Haffajee, A.D. and Socransky, S.S. (1985) Gram negative species associated with active destructive periodontal lesions. Journal of Clinical Periodontology, 12, 648-659. doi:10.1111/j.1600-051X.1985.tb00936.X

[4] Sweeney, E.A., Alcoforado, G.A., Nyman, S. and Slots, J. (1987) Prevalence and microbiology of localized prepubertal periodontitis. Oral Microbiology and Immunology, 2, 65-70. doi:10.1111/j.1399-302X.1987.tb00292.x

[5] Yoshinari, M., Oda, Y., Kato, T. and Okuda, K. (2001) Influence of surface modifications to titanium on antibacterial activity in vitro. Biomaterials, 22, 2043-2048. doi:10.1016/S0142-9612(00)00392-6

[6] Norowski, P.A. Jr. and Bumgardner, J.D. (2009) Biomaterial and antibiotic strategies for peri-implantitis: A review. Journal of Biomedical Materials Research Part B: Applied Biomaterials, 88, 530-543. doi:10.1002/jbm.b.31152

[7] Yoshinari, M., Kato, T., Matsuzaka, K., Hayakawa, T. and Shiba, K. (2010) Prevention of biofilm formation on titanium surfaces modified with conjugated molecules comprised of antimicrobial and titanium-binding peptides. Biofouling, 26, 103-110. doi:10.1080/08927010903216572

[8] Yoshinari, M., Kato, T., Matsuzaka, K., Hayakawa, T., Inoue, T., Oda, Y., Okuda, K. and Shimono, M. (2006) Adsorption behavior of antimicrobial peptide histatin 5 on PMMA. Journal of Biomedical Materials Research Part B: Applied Biomaterials, 77, 47-54. doi: $10.1002 / \mathrm{jbm}$. b.30393

[9] Miura, T., Iohara, K., Kato, T., Ishihara, K. and Yoshinari, M. (2010) Basic peptide protamine exerts antimicrobial activity against periodontopathic bacteria. Journal of Biomedical Science and Engineering, 3, 1069-1072. doi:10.4236/jbise.2010.311138

[10] Sabbioni, E., Girardi, F. and Marafante, E. (1976) Replacement of metal in metalloenzymes. A lead-alkaline phosphatase. Biochemistry, 15, 271-276. doi:10.1021/bi00647a005

[11] Erdoes, E.G. and Wohler, J.R. (1963) Inhibition in vivo of the enzymatic inactivation of bradykinin and kallidin. Biochemical Pharmacology, 12, 1193-1199. 
doi:10.1016/0006-2952(63)90094-7

[12] Lesley, S.M. and Behki, R.M. (1973) Sensitivity to myxin of Escherichia coli treated with ethylenediaminetetraacetic acid. Canadian Journal of Microbiology, 19, 531-533. doi: $10.1139 / \mathrm{m} 73-085$

[13] Cossack, Z.T. and van den Hamer, C.J. (1987) Evaluation of the EDTA-washed diet for use in the experimental production of zinc deficiency in human subjects. International Journal for Vitamin and Nutrition Research, 57, 99-102.

[14] Muralidhara and Narasimhamurthy, K. (1991) Assessment of in vivo mutagenic potency of ethylenediamine- tetraacetic acid in albino mice. Food and Chemical Toxicology, 29, 845-849. doi:10.1016/0278-6915(91)90112-K

[15] Russo, A. and Levis, A.G. (1992) Further evidence for the aneuploidogenic properties of chelating agents: Induction of micronuclei in mouse male germ cells by EDTA. Environmental and Molecular Mutagenesis, 19, 125-131. doi:10.1002/em.2850190206

[16] Oser, B.L., Oser, M. and Spencer, H.C. (1963) Safety evaluation studies of calcium EDTA. Toxicology and Applied Pharmacology, 5, 142-162.

doi:10.1016/0041-008X(63)90039-5 